\title{
Capsaicin: Physicochemical properties, cutaneous reactions and potential applications in painful and inflammatory conditions (Review)
}

\author{
MIHAELA ADRIANA ILIE ${ }^{1,2}$, CONSTANTIN CARUNTU $^{3,4}$, MIRCEA TAMPA $^{5}$, SIMONA-ROXANA GEORGESCU ${ }^{5}$, \\ CLARA MATEI $^{5}$, CAROLINA NEGREI $^{6}$, RODICA-MARIANA ION $^{7}$, CAROLINA CONSTANTIN $^{8,9}$, \\ MONICA NEAGU ${ }^{8-10}$ and DANIEL BODA ${ }^{1,4}$
}

\begin{abstract}
${ }^{1}$ Dermatology Research Laboratory, Departments of ${ }^{2}$ Biochemistry and ${ }^{3}$ Physiology, 'Carol Davila' University of Medicine and Pharmacy, Bucharest 020021; ${ }^{4}$ Department of Dermatology, 'Prof. N.C. Paulescu' National Institute of Diabetes, Nutrition and Metabolic Diseases, Bucharest 020475; ${ }^{5}$ Department of Dermatology, 'Carol Davila' University of Medicine and Pharmacy, Bucharest 020021; ${ }^{6}$ Department of Toxicology, Faculty of Pharmacy, 'Carol Davila' University of Medicine and Pharmacy, Bucharest 020956; ${ }^{7}$ The National Institute for Research and Development in Chemistry and Petrochemistry - ICECHIM, Bucharest 060021; ${ }^{8}$ Department of Immunology, 'Victor Babes' National Institute of Pathology, Bucharest 050096; ${ }^{9}$ Department of Pathology, Colentina Clinical Hospital, 020125 Bucharest;

${ }^{10}$ Department of Biochemistry, Faculty of Biology, University of Bucharest, Bucharest 020125, Romania
\end{abstract}

Received July 31, 2018; Accepted September 21, 2018

DOI: 10.3892/etm.2019.7513

\begin{abstract}
Capsaicin is a natural protoalkaloid recognized as the main pungent component in hot peppers (Capsicum annuиm L.). The capsaicin receptor is highly expressed in the unmyelinated type $\mathrm{C}$ nerve fibers originating from small diameter sensory neurons in dorsal root ganglia and cranial nerve ganglia correspondents. Capsaicin and related vanilloids have a variety of effects on primary sensory neurons function, from sensory neuron excitation characterized by local burning sensation and neurogenic inflammation, followed by conduction blockage accompanied by reversible ultrastructural changes of peripheral nociceptive endings (desensitization), going as far as irreversible degenerative changes (neurotoxicity). The main role in capsaicin-induced neurogenic inflammation relies on the capsaicin sensitive, small diameter primary sensory neurons, therefore its evaluation could be used as a diagnostic instrument in functional alterations of cutaneous sensory nerve fibers. Moreover, capsaicin-induced desensitization and neurotoxicity explain the analgesic/antinociceptive and anti-inflammatory effects of topical capsaicin and its potential use in the management of painful and inflammatory conditions. In this study, we describe the effects of
\end{abstract}

Correspondence to: Dr Monica Neagu, Department of Immunology, 'Victor Babes' National Institute of Pathology, 99-101 Splaiul Independentei, Sector 5, 050096 Bucharest, Romania

E-mail: neagu.monica@gmail.com

Key words: capsaicin, skin reactions, hyperalgesia, desensitization, neurotoxicity capsaicin on neurogenic inflammation and nociception, as well as its potential diagnostic value and therapeutic impact in various conditions involving impairment of sensory nerve fibers.

\section{Contents}

1. Introduction

2. Physicochemical properties of capsaicin

3. The capsaicin receptor - structure and functioning

4. Expression and roles of the capsaicin receptor

5. Capsaicin-induced neurogenic inflammation

6. Capsaicin-induced hyperalgesia

7. Capsaicin-induced desensitization

8. Capsaicin neurotoxicity

9. Conclusion

\section{Introduction}

Capsaicin and its related vanilloids have a complex action on primary sensory neurons with major role in physiology of pain by detection of high threshold to physical and noxious chemical stimuli, as the first step in producing the pain session (1). Initially, capsaicin induces their activation, characterized by a local burning and stinging sensation (2), possibly associated with hyperalgesia and allodynia after exposure to heat and mechanical stimuli (3). These nociceptive effects are accompanied by a localized transient inflammatory response denominated as neurogenic inflammation, activated by the neuropeptides released from the peripheral sensory nerve fibers $(2,4)$. In case of subsequent or prolonged applications 
of capsaicin, initial excitation is followed by loss of responsiveness, known as desensitization of nociceptive neurons (5), which stands at the base of analgesic/anti-nociceptive effect of topical application of capsaicin. Low-concentration topical creams, gels, lotions $(0.025,0.075$ and $0.1 \%)$ and high concentration patches $(8 \%)$ with capsaicin were developed to 'defunctionalize' cutaneous nociceptors and treat painful conditions (6). Moreover, capsaicin further depletes the neuropeptides from the sensory nerve endings and reduces the initial inflammatory response (7). Capsaicin can also induce a progressive neurotoxic degeneration of cutaneous nerves when used in high concentrations or for a long period of time $(8,9)$.

Given its analgesic and anti-nociceptive effect, capsaicin has been used in the management of neuropathic discomfort (10-17), post-herpetic neuralgia $(18,19)$, neuropathy of patients with diabetes and/or HIV (20-25), burning mouth syndrome (26), temporomandibular joint disorder (27), chemotherapy-induced peripheral neuropathy (28) and fibromyalgia (29). In trials enrolling patients with osteoarthritis and rheumatoid arthritis, topical application of capsaicin proved its efficacy and safety as an alternative to systemic analgesics, which frequently may trigger serious adverse effects $(30,31)$.

Furthermore, capsaicin-induced local inflammation can be observed and quantified using laser-Doppler flowmetry (32) and more recently through means of in vivo reflectance confocal microscopy (33), suggesting its potential diagnostic value in various functional alterations of cutaneous sensory nerve fibers $(34,35)$.

\section{Physicochemical properties of capsaicin}

Capsaicin is a natural protoalkaloid and the major pungent component of hot peppers (Capsicum annuum L.). Also known as trans-8-methyl-N-vanillyl-6-nonenamide, this chemical compound is crystalline, off-white solid, lipophilic, colorless and odorless. It has a melting point of $62-65^{\circ} \mathrm{C}$ and though not water soluble, it is soluble in ethanol, acetone, and fatty oils.

Capsaicin is a member of the vanilloid family of compounds such as vanillin (derived from vanilla), eugenol (extracted from bay leaves and cloves), and zingerone (encountered in ginger) (36,37). Capsaicin shares structural similitudes with other vanilloids, namely an aromatic ring and a long hydrophobic chain with a polar amide group (Fig. 1).

Capsaicin may also be found in fruits of other plants belonging to the genus Capsicum (38). In 1816, Bucholtz was the first to succeed extraction in solution of the pungent hot pepper compound. In 1846, the name Capsaicine was assigned to this pungent ingredient by Thresh, who also isolated it in crystalline form. After identification by Nelson in 1919, Darling and Späth established a chemical process for its synthesis as a crystalline compound with hydrophobic/lipophilic, colourless and odourless properties, in 1930 (39).

Several investigative methods are available for capsaicinoid analysis, varying from colorimetric photometry, liquid and gas chromatography, mass spectrometry, nuclear magnetic resonance, spectroscopy, amperometry, modified capillary electrophoresis, as well as olfactory electronic sensing (40-48).

High-performance liquid chromatography (HPLC) is currently employed on the largest scale, as it can provide

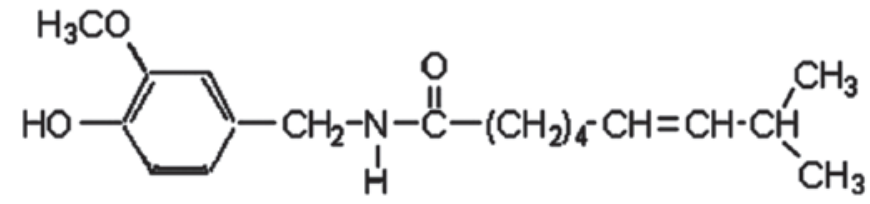

Figure 1. Chemical structure of capsaicin. Capsaicin has an aromatic ring and a long hydrophobic chain with a polar amide group.

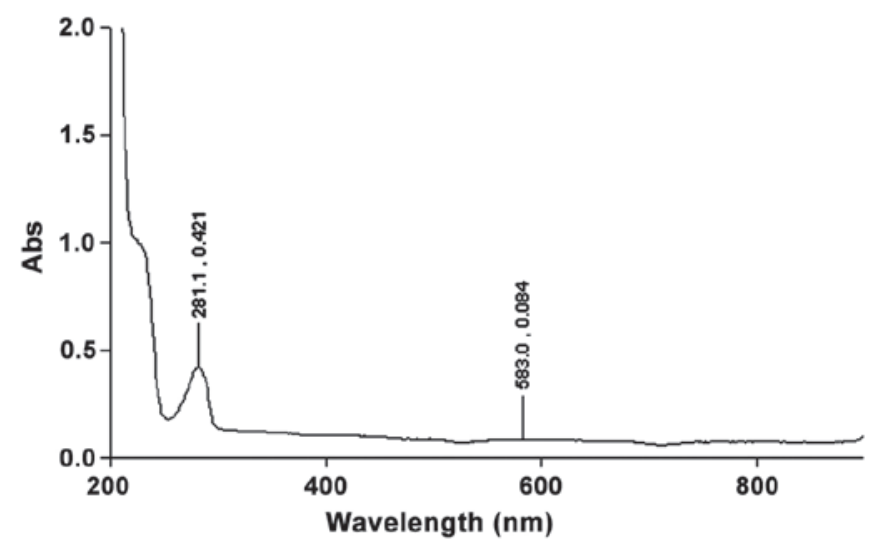

Figure 2. Absorption spectrum of Capsicum chinense Jacq. The 230 and $280 \mathrm{~nm}$ absorption peaks are characteristic to capsaicinoids and derived resins.

satisfactory reliability and accuracy, being preferred by the American Spice Trade Association (ASTA; Washington, DC, USA) as well (49).

Recently, several HPLC methodologies for capsaicin purification were published. The main capsaicinoids from Naga jolokia peppers were separated using an HPLC method with a $\mathrm{C} 18$ reverse-phase fused-core column. The separation was obtained rapidly with a gradient method with very good repeatability and precision. This method is suggested also for the separation of major capsaicinoids from commercial products that have chilli peppers (50). Using a methodology with aqueous two-phase system (ATPS) comprising an ethylene oxide-propylene oxide (EOPO) copolymer, salt and ethanol, capsaicin was extracted from capsicum oleoresin with a $95.5 \%$ yield (51).

For specimens whose concentration of capsaicin and/or related resins exceeds $700 \mathrm{ppm}$, identification and analysis by UV absorption is preferred, whilst for specimens with lower concentration fluorescence assessment is used.

UV-visible spectrophotometry is often highly sensitive, particularly for analytes with high selectivity for molar absorptivities. Fig. 2 presents the UV absorption spectrum of Capsicum chinense Jacq. extract; the wide absorption peaks at 230 and $280 \mathrm{~nm}$ are highly suggestive for capsaicinoids and derived resins.

\section{The capsaicin receptor - structure and functioning}

Capsaicin is able to link to transient receptor potential vanilloid 1 (TRPV1), mostly present in afferent neural cells (52-54). The TRPV1 receptor is a protein consisting of 838 aminoacids, with a molecular weight of $95 \mathrm{kDa}$ (containing 6 transmembrane areas and belonging to the transient receptor 
potential (TRP) family (55). TRP family has three classes: Canonical, melastatin, and vanilloid, where TRPV1 belongs to the vanilloid class group (56). TRPV1 has a pore domain created by the fifth and sixth transmembrane regions, and intracellular $\mathrm{N}$ and $\mathrm{C}$ termini $(57,58)$. TRPV1 is a non-selective cation channel with high calcium permeability (permeability sequence $\left.\mathrm{Ca}^{2+}>\mathrm{Mg}^{2+}>\mathrm{Na}^{+} \approx \mathrm{K}^{+} \approx \mathrm{Cs}^{+}\right)(59,60)$.

At intracellular level, TRPV1 is expressed in several compartments such as in the cytoplasmic membrane, endoplasmic reticulum (ER), and cytoplasmic vesicles (61). At the membrane level, TRPV1 functions as a classical receptor that generates the intracellular signaling cascade when it is activated. TRPV1 is probably stored in the cytoplasmic vesicles and upon stimulation (e.g., activation of protein kinase C), can be translocated to the membrane (61). TRPV1 function at the ER level is still under thorough research. The first findings suggested that activation of TRPV1 at the ER level increases $\mathrm{Ca}^{2+}$ mobilization from intracellular compartments and they regulate $\mathrm{Ca}^{2+}$ intracellular homeostasis $(62,63)$. Recent studies have shown that TRPV1 in ER could be involved in the ER stress-related apoptotic intracellular signaling pathway in neurodegenerative disorders (64).

TRPV1 is able to integrate various signals and has several regulators, activators, inhibitors or even compounds with dual action on TRPV1 functioning.

This receptor is activated by chemical stimuli, but also by physical triggers like temperature. It is activated by vanilloids $(65,66)$ like capsaicin and by several endogenous ligands [e.g., anandamide (67), reactive metabolites of acetaminophen, $\mathrm{N}$-arachidonoyl-dopamine (68), lipoxygenase products such as 12-hydroperoxyeicosatetraenoic acid (69)]. Activation can additionally be induced by capsaicin analogues such as resiniferatoxin, and agonists like olvanil and camphor (69-75).

The capsaicin receptor is stimulated by temperatures over $43^{\circ} \mathrm{C}$ and protons $(\mathrm{pH}<5.2)$. Moreover, heat and low $\mathrm{pH}$ sensitize its responses to other activators (76). Inflammatory mediators such as bradykinin (77) and prostaglandins prostaglandin $\mathrm{E}_{2}\left(\mathrm{PGE}_{2}\right)$ and $\mathrm{PGI}_{2}(78)$ have a facilitating effect on TRPV1. Nerve growth factor (NGF), which is released during inflammatory processes, can be associated with increased expression of TRPV1 on nociceptive neurons, and may also act directly on this receptor, increasing its response to capsaicin (79). There are various other compounds, such as histamine, serotonin, mannitol, catecholamines, botulinum neurotoxin type A and ethanol, able to potentiate TRPV1 activity (80-85). In addition, ATP reduces the temperature threshold for TRPV1 and increases responses induced by capsaicin and protons (86). At the same time, protease-activated receptor 2 (PAR2) agonists, such as trypsin and mast cell tryptase, sensitize TRPV1, increasing its response to capsaicin (87).

Inhibitors of these receptors comprise also chemical and physical factors. Hence, low temperatures strongly inhibit the activity of the TRPV1 receptor, whereas effects of TRPV1 activation may be deterred or diminished through action of capsazepine, receptor's competitive antagonist (88).

Other compounds may have dual action on TRPV1. Omega-3 fatty acids activate TRPV1 and enhance responses to low $\mathrm{pH}$ on one hand, while they may competitively inhibit vanilloid agonists' responses on the other hand. Of omega-3 fatty acids, docosahexaenoic acid mainly acts as a TRPV1 activator, whereas eicosapentaenoic acid and linolenic acid are primarily inhibitory (88).

Studies of the effect of phosphatidylinositol 4,5-bisphosphate (PIP2) on TRPV1 have also provided contradictory results: certain studies have shown PIP2 effect of reducing TRPV1 sensitivity to protons, capsaicin and heat (77), whereas other research suggests the opposite (89).

One of the intracellular communication pathways may be induced by TRPV1 sensitization mediated by PKC phosphorylation of the receptor (90) or PKA (91). The phosphorylation status of the channel plays also an important role in receptor desensitization. Channel dephosphorylation occurs through action of protein phosphatase 2A (92), and protein phosphatase 2B, known as calcineurin (93), induces an inhibitory action on TRPV1 receptor activity. In addition, other research suggests that the calmodulin $/ \mathrm{Ca}^{2+}$ complex may be involved in the channel inactivation process $(94,95)$.

However, many unknowns persist regarding the function and modulation of TRPV1 activity and further investigation is of great interest for both scientific research and clinical practice e.g., in pain control and/or neurodegenerative disorders.

\section{Expression and roles of the capsaicin receptor}

The capsaicin receptor is highly expressed in the unmyelinated type $\mathrm{C}$ nerve fibers originating from small diameter sensory neurons in dorsal root ganglia and cranial nerve ganglia correspondents (96). It can also be found in the thin myelinated A-delta fibers (97). In adult rats, the majority of neurons from the dorsal root ganglion are immunoreactive for TRPV1. The positive marking for TRPV1 has been identified at the level of both the cell membrane, inducing a cyclic pattern, and intracytoplasmic structures (98). The peripheral endings of primary sensory neurons that are positive for TRPV1 also contain proinflammatory neuropeptides, such as substance $\mathrm{P}(\mathrm{SP})$ and the calcitonin gene-related peptide (CGRP) $(4,99)$, released as result of activation. Thus, TRPV1 is involved in both nociception, by integration of various noxious stimuli, and neurogenic inflammation and inflammatory pain (74,100-102).

TRPV1 may also be found within the spinal cord and the brain, where it is involved in mediation of the sensation of pain as well as in thermoregulation (103).

Evidence from murine and human research has shown that, in addition to the nervous structures, TRPV1 is also present in other tissues as well, such as skin, adipose tissue, gastrointestinal tract, pancreatic islets, respiratory mucosa, urinary bladder, cornea, synoviocytes, myocardium, vascular smooth muscle, blood mononuclear cells. However, further studies are needed in order to clarify TRPV1 expression patterns and role in various tissues (104).

In the skin, the capsaicin receptor may work as an extraneuronal receptor (105) as it is also expressed by non-neural structures, such as keratinocytes, mast cells and dermal blood vessels (7).

In epidermal keratinocytes, activation by capsaicin induces a calcium influx (106), a similar effect being observed in human skin fibroblasts (107). Further effects of capsaicin receptor activation in keratinocytes are the result of intensified expression of cyclooxygenase-2 (COX-2) and of increased 
synthesis of IL- 8 and $\mathrm{PGE}_{2}$ (106). Capsazepine, the antagonist of TRPV1 receptor, reduces the elevation of intracellular calcium concentration and inhibits the capsaicin-induced release of these pro-inflammatory mediators. Thus, keratinocytes, via TRPV1 receptor, appear to be actively involved in inducing inflammation determined by noxious skin stimulation. It makes an interesting hypothesis that pro-inflammatory mediators synthesized and released by keratinocytes following TRPV1 activation may act on sensory skin nerve endings (108), enhancing neurogenic inflammation and nociceptive signaling. Indeed, $\mathrm{PGE}_{2}$ stimulates capsaicin-induced SP release from sensory neuron terminals (109) and prostaglandin synthesis inhibitors are able to reduce the wheal response produced by capsaicin (110). Moreover, recent research suggests that increased TRPV1 expression in human skin is involved in the photo-ageing process (111) and TRPV1 activation in keratinocytes induces an upregulation of matrix metalloproteinases leading to an increased breakdown of protein components of the extracellular matrix $(112,113)$.

Furthermore, capsaicin and TRPV1 have been proposed to be involved in mast cell activation $(114,115)$ and histamineinduced pruritus, suggesting an even more complex role of capsaicin receptor in inflammatory processes (116).

TRPV1 can also be found in skin annex structures such as hair follicles, sebaceous and sweat glands. In the hair follicles it participates in modulation of outer root sheath keratinocytes proliferation, differentiation and apoptosis (117).

\section{Capsaicin-induced neurogenic inflammation}

The main role in capsaicin-induced neurogenic inflammation is played by the peripheral endings of small diameter primary sensory neurons, which are able to release bioactive substances, thus playing an 'efferent' or 'local effector function' $(118,119)$. Upon activation, the nociceptive nerve endings can release SP and CGRP, neurokinin A, neurokinin B, somatostatin, galanin, corticotropin-releasing hormone, vasoactive intestinal peptide, and pituitary adenylate cyclase-activating polypeptide (120). Additionally, there are other substances such as cytokines and prostaglandins (106) that may be involved in this process as well.

Substances released from the nerve endings under the influence of capsaicin interact with endothelial cells, mast cells, immune cells and arteriolar smooth muscle cells, causing neurogenic inflammation characterized by redness, warmth (secondary vasodilation), swelling (induced by plasma extravasation), and hyperesthesia (secondary influence of certain sensory neurons excitability) (121). Mast cells appear to play an important role in production and expansion of capsaicin-induced inflammatory reaction. This hypothesis is supported by the close contacts between mast cells and small diameter fibers of sensory neurons sensitive to capsaicin, that were highlighted in a variety of tissues (122), and by the fact that neuropeptides released by the sensory neurons activated by capsaicin can induce mast cell degranulation (release of serotonin, proteoglycans and histamine), as well as synthesis of pro-inflammatory cytokines such as interleukins, and tumor necrosis factor- $\alpha$ (TNF- $\alpha)(123)$. These mast cell mediators can further stimulate the release of SP and other peptides from sensory nerve endings, which can induce a supplementary activation of mast cells (124). Another piece of evidence supporting mast cell involvement comes from the important decrease of capsaicin-induced inflammatory response produced by inhibitors of mast cell degranulation and by histamine or serotonin antagonists (110). This bidirectional autocatalytic loop can amplify the mast cell - sensory nerve fiber activation, eventually leading to the well-known wheal and flare reaction.

Other research suggests that, in addition to its indirect effects via substance $\mathrm{P}$ and other neuropeptides, capsaicin may also exert direct effects on mast cells (114). Capsaicin receptor was identified on the surface of mast cells, and its activation induces a calcium influx and subsequent release of pro-inflammatory cytokine IL-4. Moreover, it can induce mast cell desensitization in case of further stimulation.

Another contribution to capsaicin-induced inflammation can be related to its vascular effects. For example, an in vitro study on human umbilical vein endothelial cells has shown that capsaicin increases both expression and secretion of CGRP, a potent vasodilator and this process is mediated by TRPV1 (125).

\section{Capsaicin-induced hyperalgesia}

In addition to local inflammation accompanied by the sensation of pain, hyperalgesia is another possible effect of capsaicin administration to the skin. Primary hyperalgesia has been described, occurring on administration area (126-129), as well as secondary hyperalgesia, arising in adjacent regions (130). Primary hyperalgesia is manifested by an exaggerated response to different stimuli, such as thermal or mechanic $(131,132)$. The mechanisms of primary hyperalgesia induced by capsaicin are complex and not completely understood. One of the theories that have tried to explain this phenomenon argues that the main mechanism directly involved is sensitization of nociceptive nerve endings that undergo capsaicin action. There is experimental evidence supporting this hypothesis. Use of capsaicin on a single type $\mathrm{C}$ nerve fiber induces sensitization of this specific nerve fiber and not of the other adjacent nerve endings that have not been exposed to capsaicin (133). These results highlight the ability of capsaicin to cause direct sensitization of nociceptive nerve endings.

Secondary hyperalgesia has been described primarily to mechanical stimuli (129) and is probably determined by sensitization of dorsal horn neurons in the spinal cord (134). Another hypothesis regarding the mechanism of secondary hyperalgesia production supports the involvement of 'silent' nociceptor-free nerve endings of unmyelinated type $\mathrm{C}$ fibers that can respond to noxious stimuli only after their recruitment through pro-inflammatory mediators (135). In addition to activation and sensitization of multimodal nociceptors, other peripheral nerve mechanisms that may modulate the sensation of pain and hyperalgesia induced by capsaicin also include activation of $\alpha$-adrenergic receptors, local application of norepinephrine enhancing the painful effects of capsaicin (136).

Involvement of TRPV1/other vanilloid receptors in inflammation-associated pain is increasingly acknowledged $(102,137)$. Experimental data show that TRPV1 is required for the thermal hyperalgesia associated with acute 
inflammation $(102,138)$. Hyperalgesia develops in certain pathological conditions characterized by an increased expression of TRPV1 but the mechanisms involved are yet revealed only in part $(77,139)$. For example, in post-inflammatory states or some clinical pain conditions, the increase in TRPV1 is associated with higher levels of NGF and glial cell-derived neurotropic factor (GDNF). Moreover, peripheral production of NGF with an enhanced retrograde transport of NGF to the neuronal cell body activates p38 MAPK in the primary neurons, inducing an increased expression of TRPV1 in the nociceptive nerve endings and further thermal hypersensitivity (140-144). The occurrence of thermal hyperalgesia also involves sensitization of existing peripheral TRPV1 channels by a number of mediators such as protons (during states of tissue injury or ischemia), prostaglandins, including $\mathrm{PGE}_{2}$ and PGI2 bradykinin (BK), ATP, and endothelin (ET)-1, possibly also responsible for the persistent burning pain often encountered in clinical practice $(78,145,146)$.

\section{Capsaicin-induced desensitization}

Mechanisms underlying desensitization and numbness resulting from treatment with capsaicin are still not well understood. One possibility is depletion of neuropeptides SP and CGRP from type $\mathrm{C}$ nerve fibers, leading to desensitization of nociceptors, as capsaicin is known to trigger the release of these peptides from primary afferent terminals $(118,121)$. However, electrophysiological studies suggest that initial rapid desensitization would be the effect of capsaicin on sensory neurons ion channels.

Capsaicin excites nociceptors by interacting with its receptor TRPV1 (147), inducing depolarization of sensory neurons. The membrane permeability to ions increases, a process involving mainly calcium ion channels $(148,149)$. This is followed by inactivation of voltage-gated ion channels, which affects the formation of action potentials that is possibly responsible for the initial rapid desensitization and subsequent hypoesthesia. Moreover, capsaicin may also interfere with formation of action potentials by inducing mitochondrial ultrastructural alterations in the nociceptive endings as a consequence of prolonged activation of ion channels (9).

There are two types of desensitization resulting from capsaicin application: i) pharmacological desensitization under repeated or prolonged application of capsaicin, leading to gradual reduction of subsequent responses to capsaicin; and ii) functional desensitization, in which capsaicin decreases neuronal sensitivity to a variety of noxious stimuli (heat, pressure, chemical irritants, endogenous or exogenous agents). Though often occurring together, the two phenomena can be separated on very low capsaicin concentrations. In such circumstances, the ability to elicit a response to capsaicin is selectively diminished or abolished, while the response to other stimuli remains unaltered (150). Functional desensitization arising on increased concentrations of capsaicin is considered the foundation for the analgesic and anti-inflammatory effects of capsaicin.

Although initially stimulating the release of neuropeptides, capsaicin has a long-term inhibitory effect on the efferent function of sensory neurons, which may underlie its analgesic and anti-inflammatory actions. Following capsaicin application, injurious stimuli no longer trigger the release of neurotransmitters and neuropeptides, in spite of the nearly normal levels of neuropeptides in the sensory nerve endings (151-153). Inflammation arising from the injection of histamine and vasoactive agents SP, VIP and somatostatin were also reduced in skin previously treated with capsaicin (151-153).

This long-term inhibitory effect of capsaicin has also been connected to inhibition of voltage-gated calcium channels $(148,149)$ at the level of central and peripheral nerve endings. From animal studies, it appears that the efferent function of sensory neurons is preferentially inhibited by capsaicin, suggesting a higher sensitivity to capsaicin for the mechanism of peptide release as compared to the process of sensory transmission. Another possible explanation is the involvement of different nerve fiber subpopulations in this process (154).

\section{Capsaicin neurotoxicity}

Capsaicin elicits a wide variety of effects on the sensory neurons ranging from excitation to conduction blockage accompanied by reversible ultrastructural changes and going up to apoptosis and irreversible changes, such as mitochondrial damage and intracellular release of reactive oxygen species triggering DNA fragmentation and activation of the caspase cascade (155-157).

Capsaicin-induced neurotoxicity may arise at high doses, administered systemically or topically (injected intradermally) (9). The first studies on capsaicin neurotoxic effects have demonstrated that systemic administration of high-dose capsaicin in either adult or new-born rats causes degeneration of a subset of primary afferent small diameter fibers and their cell bodies $(118,158)$. In humans, systemic administration of capsaicin was proven to induce a certain degree of degeneration of the sub-epidermal nerve plexus (159), indicating the susceptibility of skin nerve fibers to the neurotoxic effects of capsaicin. Intradermal injection of capsaicin produces a rapid, dose-dependent degeneration of epidermal and sub-epidermal nerve fibers; such degeneration is limited to the injection site and only to the nerve fibers in direct contact with capsaicin (9). This progressive denervation occurs during the first two weeks after the injection and can be highlighted by the loss of protein gene product 9.5 (PGP 9.5) immunoreactive nerve fibers. For capsaicin in low doses, denervation is mainly limited to the epidermis, whereas administration of higher doses determines a complete loss of epidermal PGP 9.5 immunoreactive nerve fibers and injury of various degrees of sub-epidermal nerve fibers (9). Moreover, $72 \mathrm{~h}$ after capsaicin injection, a loss of immunoreactivity for CGRP and a decrease of nerve fibers immunoreactive for SP can be observed. Reduction of epidermal nerve fibers is associated with a reduced pain sensation from heat and mechanical stimulation, capsaicin exerting a greater effect on pain from heat stimulation. The touch threshold is not significantly modified following injection of capsaicin (9).

Reinnervation of the epidermis begins during the first 3-4 weeks after capsaicin injection and is characterized by re-emergence of an intact sub-epidermal nerve plexus, of CGRP immunoreactive nerve fibers and scarce intraepidermal fibers. At the same time, one can observe the gradual restoration of pain sensation induced by heat and mechanical stimuli. 
Immunoreactivity for PGP 9.5 is gradually restored and is associated with progressive regeneration of the sub-epidermal nervous plexus and with reinnervation of the epidermis, although the number of regenerated fibers immunoreactive for PGP 9.5 is lower than that of normal skin, even 4 to 6 weeks following capsaicin injection. The loss and further reoccurrence of immunoreactivity for PGP 9.5 is correlated with loss and recovery of somatic sensations (9).

Epidermal nerve fiber degeneration occurs also after topical administration of capsaicin, although slower and less intense than that produced by intradermal injection (8). Because of capsaicin capacity to diffuse, degeneration only develops at the application site and in the fibers directly exposed to the neurotoxin. Moreover, degeneration develops progressively, epidermal nerve fibers being affected $24 \mathrm{~h}$ after capsaicin administration, while sub-epidermal nerve plexus and nerve fibers immunoreactive for CGRP and SP after 1 week. This phenomenon has been well illustrated in a study in which multiple topical applications of capsaicin caused progressive degeneration of the nerve fibers in the epidermis (8).

Mechanisms underlying neurotoxicity evoked by capsaicin were investigated in vitro using cell cultures of DRG neurons as well as in vivo using murine experimental models (160). Studies revealed that capsaicin-induced alterations are caused by both osmotic changes and alterations of calcium influx levels, inducing activation of calcium-sensitive proteases (160). Moreover, unlike adult sensory neurons, the presence of NGF is necessary for the survival of immature neurons in the dorsal root ganglia and administration of capsaicin in neonate rats leads to destruction of most primary nociceptive neurons, probably by disrupting intra-axonal transport of NGF (155).

\section{Conclusion}

Capsaicin, the major pungent ingredient of hot peppers activates TRPV1 receptor that is widely expressed in the cutaneous peripheral sensory nerve fibers. At first topical application, capsaicin induces a local burning sensation, associated with allodynia and hyperesthesia and a transient inflammatory response secondary to the release of neuromodulators from the sensory nerve fibers. The extent of the local inflammatory reaction can be quantified noninvasively and seems a promising diagnostic tool in functional alterations of cutaneous sensory nerve fibers. Repeated applications of capsaicin lead to desensitization of nociceptive neurons, gradual reduction of the inflammatory response and further to neurotoxic degeneration of cutaneous nerve fibers when used in high concentrations. These effects explain the analgesic/ anti-nociceptive and anti-inflammatory effects of topical capsaicin and its potential use in the management of painful and inflammatory conditions.

\section{Acknowledgements}

Not applicable.

\section{Funding}

This study was supported by a grant of the Romanian National Authority for Scientific Research and Innovation (CNCS/
CCCDI - UEFISCDI, project no. PN-III-P2-2.1-BG-2016-0443, 120BG/01.10.2016, PN-III-P1-1.2-PCCDI-2017-0341) financed by the Executive Agency for Higher Education, Research, Development and Innovation, and PN 18.21.02.02/2018 financed by the Ministry of Research and Innovation (Bucharest Romania).

\section{Availability of data and materials}

The datasets used and/or analyzed during the current study are available from the corresponding author on reasonable request.

\section{Authors' contributions}

MAI, CC, MN were responsible for the research creation and design, data acquisition, analysis and interpretation of data, statistical analysis and contributed to drafting the manuscript, and revising it critically for important intellectual content. MT and SRG contributed to the data acquisition, analysis and interpretation of data, drafting the manuscript, and revising it critically for important intellectual content. CM, CC, CN and RMI were responsible for the analysis and interpretation of data, statistical analysis, drafting the manuscript, and revising it critically for important intellectual content. DB contributed to the research creation and design, analysis and interpretation of data, drafting the manuscript, and revising it critically for important intellectual content. All authors agreed to be accountable for all aspects of the work in ensuring that questions related to the accuracy or integrity of any part of the work are appropriately investigated and resolved.

\section{Ethics approval and consent to participate}

Not applicable.

\section{Patient consent for publication}

Not applicable.

\section{Competing interests}

The authors declare that they have no competing interests.

\section{References}

1. Dubin AE and Patapoutian A: Nociceptors: The sensors of the pain pathway. J Clin Invest 120: 3760-3772, 2010.

2. Căruntu C, Negrei C, Ghiţă MA, Căruntu A, Bădărău AI, Buraga I, Boda D, Albu A and Brănişteanu D: Capsaicin, a hot topic in skin pharmacology and physiology. Farmacia 63: 487-491, 2015.

3. du Jardin KG, Gregersen LS, Røsland T, Uggerhøj KH, Petersen LJ, Arendt-Nielsen L and Gazerani P: Assessment of pain response in capsaicin-induced dynamic mechanical allodynia using a novel and fully automated brushing device. Pain Res Manag 18: 6-10, 2013.

4. Caruntu C, Boda D, Musat S, Caruntu A, Poenaru E, Calenic B, Savulescu-Fiedler I, Draghia A, Rotaru M and Badarau AI: Stress effects on cutaneous nociceptive nerve fibers and their neurons of origin in rats. Rom Biotechnol Lett 19: 9517-9530, 2014.

5. Szallasi A and Blumberg PM: Vanilloid (Capsaicin) receptors and mechanisms. Pharmacol Rev 51: 159-212, 1999.

6. Derry S, Rice AS, Cole P, Tan T and Moore RA: Topical capsaicin (high concentration) for chronic neuropathic pain in adults. Cochrane Database Syst Rev 1: CD007393, 2017. 
7. Ständer S, Moormann C, Schumacher M, Buddenkotte J, Artuc M, Shpacovitch V, Brzoska T, Lippert U, Henz BM, Luger TA, et al: Expression of vanilloid receptor subtype 1 in cutaneous sensory nerve fibers, mast cells, and epithelial cells of appendage structures. Exp Dermatol 13: 129-139, 2004

8. Nolano M, Simone DA, Wendelschafer-Crabb G and Kennedy WR: Decreased sensation and loss of epidermal nerve fibers following repeated topical application of capsaicin in humans. Soc Neurosci Abstr 22: 1802, 1996.

9. Simone DA, Nolano M, Johnson T, Wendelschafer-Crabb G and Kennedy WR: Intradermal injection of capsaicin in humans produces degeneration and subsequent reinnervation of epidermal nerve fibers: Correlation with sensory function. J Neurosci 18 : 8947-8959, 1998

10. Mankowski C, Poole CD, Ernault E, Thomas R, Berni E, Currie CJ, Treadwell C, Calvo JI, Plastira C, Zafeiropoulou E, et al: Effectiveness of the capsaicin $8 \%$ patch in the management of peripheral neuropathic pain in European clinical practice: The ASCEND study. BMC Neurol 17: 80, 2017.

11. Burness CB and McCormack PL: Capsaicin $8 \%$ patch: A review in peripheral neuropathic pain. Drugs 76: 123-134, 2016.

12. Haanpää M, Cruccu G, Nurmikko TJ, McBride WT, Docu Axelarad A, Bosilkov A, Chambers C, Ernault E and Abdulahad AK: Capsaicin 8\% patch versus oral pregabalin in patients with peripheral neuropathic pain. Eur J Pain 20: 316-328, 2016.

13. Giménez-Milà M, Videla S, Navarro MA, Faulí A, Ojeda A, Bogdanovich A, Moreno LA, Hernández-Cera C and Busquets C: Assessment of the feasibility of high-concentration capsaicin patches in the pain unit of a tertiary hospital for a population of mixed refractory peripheral neuropathic pain syndromes in non-diabetic patients. BMC Anesthesiol 14: 120, 2014

14. Zis P, Apsokardos A, Isaia C, Sykioti P and Vadalouca A: Posttraumatic and postsurgical neuropathic pain responsive to treatment with capsaicin 8\% topical patch. Pain Physician 17: E213-E218, 2014.

15. Serrano A, Torres D, Veciana M, Caro C, Montero J and Mayoral V: Quantitative thermal testing profiles as a predictor of treatment response to topical capsaicin in patients with localized neuropathic pain. Pain Res Treat 2017: 7425907, 2017.

16. Bauchy F, Mouraux A, Deumens R, Leerink M, Ulpiano Trillig A le Polain de Waroux B, Steyaert A, Joëlle QL and Forget P: Feasibility of topical applications of natural high-concentration capsaicinoid solutions in patients with peripheral neuropathic pain: A retrospective analysis. Pain Res Manag 2016: 9703036 , 2016.

17. Baranidharan G, Das S and Bhaskar A: A review of the high-concentration capsaicin patch and experience in its use in the management of neuropathic pain. Ther Adv Neurol Disorder 6: 287-297, 2013.

18. Yong YL, Tan LT, Ming LC, Chan KG, Lee LH, Goh BH and Khan TM: The effectiveness and safety of topical capsaicin in postherpetic neuralgia: A systematic review and meta-analysis. Front Pharmacol 7: 538, 2017.

19. Boyd K, Shea SM and Patterson JW: The role of capsaicin in dermatology. In: Capsaicin as a Therapeutic Molecule. Springer, Basel, pp293-306, 2014

20. Ostrovsky DA: Single treatment with capsaicin $8 \%$ patch may reduce pain and sleep interference up to 12 weeks in patients with painful diabetic peripheral neuropathy. Explore (NY) 13: 351-353, 2017.

21. Gálvez R, Navez ML, Moyle G, Maihöfner C, Stoker M, Ernault E, Nurmikko TJ and Attal N: Capsaicin $8 \%$ patch repeat treatment in nondiabetic peripheral neuropathic pain: A 52-week, open-label, single-arm, safety study. Clin J Pain 33: 921-931, 2017.

22. Kiani J, Ahmad Nasrollahi S, Esna-Ashari F, Fallah P and Sajedi F: Amitriptyline 2\% cream vs. capsaicin $0.75 \%$ cream in the treatment of painful diabetic neuropathy (Double blind, randomized clinical trial of efficacy and safety). Iran J Pharm Res 14: 1263-1268, 2015.

23. Kulkantrakorn K, Lorsuwansiri C and Meesawatsom P: $0.025 \%$ capsaicin gel for the treatment of painful diabetic neuropathy: A randomized, double-blind, crossover, placebo-controlled trial Pain Pract 13: 497-503, 2013

24. Brown S, Simpson DM, Moyle G, Brew BJ, Schifitto G Larbalestier N, Orkin C, Fisher M, Vanhove GF and Tobias JK: NGX-4010, a capsaicin 8\% patch, for the treatment of painful HIV-associated distal sensory polyneuropathy: Integrated analysis of two phase III, randomized, controlled trials. AIDS Res Ther 10: 5, 2013.
25. Simpson DM, Brown S, Tobias JK and Vanhove GF; NGX-4010 C107 Study Group: NGX-4010, a capsaicin $8 \%$ dermal patch, for the treatment of painful HIV-associated distal sensory polyneuropathy: Results of a 52-week open-label study. Clin J Pain 30: 134-142, 2014.

26. Feller L, Fourie J, Bouckaert M, Khammissa RAG, Ballyram R and Lemmer J: Burning mouth syndrome: Aetiopathogenesis and principles of management. Pain Res Manag 2017: 1926269, 2017.

27. Campbell BK, Fillingim RB, Lee S, Brao R, Price DD and Neubert JK: Effects of high-dose capsaicin on TMD subjects: A randomized clinical study. JDR Clin Trans Res 2: 58-65, 2017.

28. Filipczak-Bryniarska I, Krzyzewski RM, Kucharz J, Michalowska-Kaczmarczyk A, Kleja J, Woron J, Strzepek K, Kazior L, Wordliczek J, Grodzicki T, et al: High-dose 8\% capsaicin patch in treatment of chemotherapy-induced peripheral neuropathy: Single-center experience. Med Oncol 34: 162, 2017.

29. Casanueva B, Rodero B, Quintial C, Llorca J and GonzálezGay MA: Short-term efficacy of topical capsaicin therapy in severely affected fibromyalgia patients. Rheumatol Int 33: 2665$2670,2013$.

30. Deal CL, Schnitzer TJ, Lipstein E, Seibold JR, Stevens RM, Levy MD, Albert D and Renold F: Treatment of arthritis with topical capsaicin: A double-blind trial. Clin Ther 13: 383-395, 1991.

31. Laslett LL and Jones G: Capsaicin for osteoarthritis pain. In: Capsaicin as a Therapeutic Molecule. Springer, Basel, pp277-291, 2014.

32. Caselli A, Spallone V, Marfia GA, Battista C, Pachatz C, Veves A and Uccioli L: Validation of the nerve axon reflex for the assessment of small nerve fibre dysfunction. J Neurol Neurosurg Psychiatry 77: 927-932, 2006.

33. Căruntu C and Boda D: Evaluation through in vivo reflectance confocal microscopy of the cutaneous neurogenic inflammatory reaction induced by capsaicin in human subjects. J Biomed Opt 17: 085003, 2012

34. Căruntu C, Negrei C, Boda D, Constantin C, Căruntu A and Neagu M: Biotechnological advances for diagnosis of peripheral diabetic neuropathy. Rom Biotechnol Lett 19: 9846-9858, 2014.

35. Adriana Ghita M, Caruntu C, Lixandru D, Pitea A, Batani A and Boda D: The quest for novel biomarkers in early diagnosis of diabetic neuropathy. Curr Proteomics 14: 86-99, 2017.

36. Fattori V, Hohmann MS, Rossaneis AC, Pinho-Ribeiro FA and Verri WA: Capsaicin: Current understanding of its mechanisms and therapy of pain and other pre-clinical and clinical uses. Molecules 21: 844, 2016.

37. Rollyson WD, Stover CA, Brown KC, Perry HE, Stevenson CD, McNees CA, Ball JG, Valentovic MA and Dasgupta P: Bioavailability of capsaicin and its implications for drug delivery. J Control Release 196: 96-105, 2014.

38. Reyes-Escogido ML, Gonzalez-Mondragon EG and VazquezTzompantzi E: Chemical and pharmacological aspects of capsaicin. Molecules 16: 1253-1270, 2011.

39. Bode AM and Dong Z: The two faces of capsaicin. Cancer Res 71: 2809-2814, 2011

40. North H: Colorimetric determination of capsaicin in oleoresin of capsicum. Anal Chem 21: 934-936, 1949.

41. Hartman KT: A rapid gas-liquid chromatographic determination for capsaicin in capsicum spices. J Food Sci 35: 543-547, 1970.

42. Cooper TH, Guzinski JA and Fisher C: Improved highperformance liquid chromatography method for the determination of major capsaicinoids in capsicum oleoresins. J Agric Food Chem 39: 2253-2256, 1991.

43. Iwai K, Suzuki T, Fujiwake H and Oka S: Simultaneous microdetermination of capsaicin and its four analogues by using high-performance liquid chromatography and gas chromatography - mass spectrometry. J Chromatogr A 172: 303-311, 1979.

44. Nyberg NT, Baumann H and Kenne L: Application of solid-phase extraction coupled to an NMR flow-probe in the analysis of HPLC fractions. Magn Reson Chem 39: 236-240, 2001.

45. Nikolaeva DA: Spectrophotometric determination of capsaicin in peppers (Capsicum annuum L.). Biokhim. Metody Analiza Plodov, Kishinev, pp99-102, 1984.

46. Pryakhin OR, Tkach VI, Golovkin VA, Gladyshev VV and Kuleshova ND: Method for determination of the total amount of capsaicinoids in thick red pepper extract by amperometric titration. U.S.S.R. 90: 4880330, 1992.

47. Laskaridou-Monnerville A: Determination of capsaicin and dihydrocapsaicin by micellar electrokinetic capillary chromatography and its application to various species of Capsicum, Solanaceae. J Chromatogr A 838: 293-302,1999. 
48. Korel F, Bağdatlioğlu N, Balaban MÖ and Hişil Y: Ground red peppers: Capsaicinoids content, Scoville scores, and discrimination by an electronic nose. J Agric Food Chem 50: 3257-3261, 2002.

49. Way RM: Official Analytical Methods of the American SpiceTrade Association. Vol. 3. American Spice Trade Association, Washington, DC, pp51-52, 1985.

50. Stipcovich T, Barbero GF, Ferreiro-González M, Palma M and Barroso CG: Fast analysis of capsaicinoids in Naga Jolokia extracts (Capsicum chinense) by high-performance liquid chromatography using fused core columns. Food Chem 239: 217-224 2018.

51. Fan Y, Lu YM, Yu B, Tan CP and Cui B: Extraction and purification of capsaicin from capsicum oleoresin using an aqueous two-phase system combined with chromatography. J Chromatogr B Analyt Technol Biomed Life Sci 1063: 11-17, 2017.

52. Darré $L$ and Domene C: Binding of capsaicin to the TRPV1 ion channel. Mol Pharm 12: 4454-4465, 2015.

53. Srinivasan K: Biological activities of red pepper (Capsicum annuum) and its pungent principle capsaicin: A review. Crit Rev Food Sci Nutr 56: 1488-1500, 2016.

54. Clapham DE: TRP channels as cellular sensors. Nature 426: 517-524, 2003.

55. Szolcsányi J and Jancsó-Gábor A: Sensory effects of capsaicin congeners I. Relationship between chemical structure and painproducing potency of pungent agents. Arzneimittelforschung 25: $1877-1881,1975$

56. Montell C, Birnbaumer L and Flockerzi V: The TRP channels, a remarkably functional family. Cell 108: 595-598, 2002.

57. Ferrer-Montiel A, García-Martínez C, Morenilla-Palao C, García-Sanz N, Fernández-Carvajal A, Fernández-Ballester G and Planells-Cases R: Molecular architecture of the vanilloid receptor. Insights for drug design. Eur J Biochem 271: 1820-1826, 2004.

58. García-Sanz N, Fernández-Carvajal A, Morenilla-Palao C, Planells-Cases R, Fajardo-Sánchez E, Fernández-Ballester G and Ferrer-Montiel A: Identification of a tetramerization domain in the $\mathrm{C}$ terminus of the vanilloid receptor. J Neurosci 24: $5307-5314,2004$

59. Song S, Ayon RJ, Yamamura A, Yamamura H, Dash S, Babicheva A, Tang H, Sun X, Cordery AG, Khalpey Z, et al: Capsaicin-induced $\mathrm{Ca}^{2+}$ signaling is enhanced via upregulated TRPV1 channels in pulmonary artery smooth muscle cells from patients with idiopathic PAH. Am J Physiol Lung Cell Mol Physiol 312: L309-L325, 2017.

60. Caterina MJ and Julius D: The vanilloid receptor: A molecular gateway to the pain pathway. Annu Rev Neurosci 24: 487-517, 2001.

61. Morenilla-Palao C, Planells-Cases R, García-Sanz N and Ferrer-Montiel A: Regulated exocytosis contributes to protein kinase $\mathrm{C}$ potentiation of vanilloid receptor activity. J Biol Chem 279: 25665-25672, 2004.

62. Kárai LJ, Russell JT, Iadarola MJ and Oláh Z: Vanilloid receptor 1 regulates multiple calcium compartments and contributes to $\mathrm{Ca}^{2+}$-induced $\mathrm{Ca}^{2+}$ release in sensory neurons. J Biol Chem 279: 16377-16387, 2004.

63. Marshall IC, Owen DE, Cripps TV, Davis JB, McNulty S and Smart D: Activation of vanilloid receptor 1 by resiniferatoxin mobilizes calcium from inositol 1,4,5-trisphosphate-sensitive stores. Br J Pharmacol 138: 172-176, 2003.

64. Vrechi TA, Crunfli F, Costa AP and Torrão AS: Cannabinoid receptor type 1 agonist ACEA protects neurons from death and attenuates endoplasmic reticulum stress-related apoptotic pathway signaling. Neurotox Res 33: 846-855, 2018.

65. Van Der Stelt M and Di Marzo V: Endovanilloids. Putative endogenous ligands of transient receptor potential vanilloid 1 channels. Eur J Biochem 271: 1827-1834, 2004.

66. Kim SR, Lee DY, Chung ES, Oh UT, Kim SU and Jin BK: Transient receptor potential vanilloid subtype 1 mediates cell death of mesencephalic dopaminergic neurons in vivo and in vitro. J Neurosci 25: 662-671, 2005

67. Smart D, Gunthorpe MJ, Jerman JC, Nasir S, Gray J, Muir AI, Chambers JK, Randall AD and Davis JB: The endogenous lipid anandamide is a full agonist at the human vanilloid receptor (hVR1). Br J Pharmacol 129: 227-230, 2000.

68. Marinelli S, Di Marzo V, Florenzano F, Fezza F, Viscomi MT, van der Stelt M, Bernardi G, Molinari M, Maccarrone M and Mercuri NB: N-arachidonoyl-dopamine tunes synaptic transmission onto dopaminergic neurons by activating both cannabinoid and vanilloid receptors. Neuropsychopharmacology 32 298-308, 2007.
69. Hwang SW, Cho H, Kwak J, Lee SY, Kang CJ, Jung J, Cho S, Min KH, Suh YG, Kim D, et al: Direct activation of capsaicin receptors by products of lipoxygenases: Endogenous capsaicinlike substances. Proc Natl Acad Sci USA 97: 6155-6160, 2000.

70. Eberhardt MJ, Schillers F, Eberhardt EM, Risser L, de la Roche J, Herzog C, Echtermeyer F and Leffler A: Reactive metabolites of acetaminophen activate and sensitize the capsaicin receptor TRPV1. Sci Rep 7: 12775, 2017.

71. Smutzer G and Devassy RK: Integrating TRPV1 receptor function with capsaicin psychophysics. Adv Pharmacol Sci 2016: 1512457, 2016.

72. Elokely K, Velisetty P, Delemotte L, Palovcak E, Klein ML, Rohacs T and Carnevale V: Understanding TRPV1 activation by ligands: Insights from the binding modes of capsaicin and resiniferatoxin. Proc Natl Acad Sci USA 113: E137-E145, 2016.

73. Nagy I, Friston D, Valente JS, Torres Perez JV and Andreou AP: Pharmacology of the capsaicin receptor, transient receptor potential vanilloid type-1 ion channel. Prog Drug Res 68: 39-76, 2014.

74. Tominaga M, Caterina MJ, Malmberg AB, Rosen TA, Gilbert H, Skinner K, Raumann BE, Basbaum AI and Julius D: The cloned capsaicin receptor integrates multiple pain-producing stimuli. Neuron 21: 531-543, 1998

75. Moreira FA, Aguiar DC, Terzian AL, Guimarães FS and Wotjak CT: Cannabinoid type 1 receptors and transient receptor potential vanilloid type 1 channels in fear and anxiety-two sides of one coin? Neuroscience 204: 186-192, 2012.

76. Ryu S, Liu B and Qin F: Low pH potentiates both capsaicin binding and channel gating of VR1 receptors. J Gen Physiol 122: 45-61, 2003.

77. Chuang HH, Prescott ED, Kong H, Shields S, Jordt SE, Basbaum AI, Chao MV and Julius D: Bradykinin and nerve growth factor release the capsaicin receptor from PtdIns $(4,5)$ P2-mediated inhibition. Nature 411: 957-962, 2001

78. Moriyama T, Higashi T, Togashi K, Iida T, Segi E, Sugimoto Y, Tominaga T, Narumiya $S$ and Tominaga M: Sensitization of TRPV1 by EP1 and IP reveals peripheral nociceptive mechanism of prostaglandins. Mol Pain 1: 3, 2005.

79. Zhang $X$, Huang $J$ and McNaughton PA: NGF rapidly increases membrane expression of TRPV1 heat-gated ion channels. EMBO J 24: 4211-4223, 2005.

80. Nakagawa $\mathrm{H}$ and Hiura A: Four possible itching pathways related to the TRPV1 channel, histamine, PAR-2 and serotonin. Malays J Med Sci 20: 5-12, 2013

81. Bertrand H, Kyriazis M, Reeves KD, Lyftogt $\mathbf{J}$ and Rabago D: Topical mannitol reduces capsaicin-induced pain: Results of a pilot-level, double-blind, randomized controlled trial. PM R 7: 1111-1117, 2015.

82. Luvisetto S, Vacca V and Cianchetti C: Analgesic effects of botulinum neurotoxin type A in a model of allyl isothiocyanate- and capsaicin-induced pain in mice. Toxicon 94: 23-28, 2015.

83. Matak I, Rossetto O and Lacković Z: Botulinum toxin type A selectivity for certain types of pain is associated with capsaicin-sensitive neurons. Pain 155: 1516-1526, 2014.

84. Arout CA, Perrino AC Jr, Ralevski E, Acampora G, Koretski J, Limoncelli D, Newcomb J and Petrakis IL: Effect of intravenous ethanol on capsaicin-induced hyperalgesia in human subjects. Alcohol Clin Exp Res 40: 1425-1429, 2016.

85. Filippi A, Caruntu C, Gheorghe RO, Deftu A, Amuzescu B and Ristoiu V: Catecholamines reduce transient receptor potential vanilloid type 1 desensitization in cultured dorsal root ganglia neurons. J Physiol Pharmacol 67: 843-850, 2016.

86. Tominaga M, Wada M and Masu M: Potentiation of capsaicin receptor activity by metabotropic ATP receptors as a possible mechanism for ATP-evoked pain and hyperalgesia. Proc Natl Acad Sci USA 98: 6951-6956, 2001.

87. Amadesi S, Nie J, Vergnolle N, Cottrell GS, Grady EF, Trevisani M, Manni C, Geppetti P, McRoberts JA, Ennes H, et al: Protease-activated receptor 2 sensitizes the capsaicin receptor transient receptor potential vanilloid receptor 1 to induce hyperalgesia. J Neurosci 24: 4300-4312, 2004.

88. Matta JA, Miyares RL and Ahern GP: TRPV1 is a novel target for omega-3 polyunsaturated fatty acids. J Physiol 578: 397-411, 2007.

89. Sowa NA, Street SE, Vihko P and Zylka MJ: Prostatic acid phosphatase reduces thermal sensitivity and chronic pain sensitization by depleting phosphatidylinositol 4,5-bisphosphate. J Neurosci 30: 10282-10293, 2010.

90. Premkumar LS and Ahern GP: Induction of vanilloid receptor channel activity by protein kinase C. Nature 408: 985-990, 2000. 
91. Bhave G, Zhu W, Wang H, Brasier DJ, Oxford GS and Gereau RW IV: cAMP-dependent protein kinase regulates desensitization of the capsaicin receptor (VR1) by direct phosphorylation. Neuron 35: 721-731, 2002

92.Zhang X, Wu J, Fang L and Willis WD: The effects of protein phosphatase inhibitors on the duration of central sensitization of rat dorsal horn neurons following injection of capsaicin. Mol Pain 2: 23, 2006.

93.Por ED, Samelson BK, Belugin S, Akopian AN, Scott JD and Jeske NA: PP2B/calcineurin-mediated desensitization of TRPV1 does not require AKAP150. Biochem J 432: 549-556, 2010.

94.Numazaki M, Tominaga T, Takeuchi K, Murayama N, Toyooka H and Tominaga M: Structural determinant of TRPV1 desensitization interacts with calmodulin. Proc Natl Acad Sci USA 100: 8002-8006, 2003.

95.Pecze L, Blum W and Schwaller B: Mechanism of capsaicin receptor TRPV1-mediated toxicity in pain-sensing neurons focusing on the effects of $\mathrm{Na}(+) / \mathrm{Ca}(2+)$ fluxes and the $\mathrm{Ca}(2+)$ binding protein calretinin. Biochim Biophys Acta 1833 1680-1691, 2013.

96. Kobayashi K, Fukuoka T, Obata K, Yamanaka H, Dai Y, Tokunaga A and Noguchi K: Distinct expression of TRPM8, TRPA1, and TRPV1 mRNAs in rat primary afferent neurons with adelta/c-fibers and colocalization with trk receptors. J Comp Neurol 493: 596-606, 2005.

97.Lumpkin EA and Caterina MJ: Mechanisms of sensory transduction in the skin. Nature 445: 858-865, 2007.

98. Hong S, Morrow TJ, Paulson PE, Isom LL and Wiley JW: Early painful diabetic neuropathy is associated with differential changes in tetrodotoxin-sensitive and -resistant sodium channels in dorsal root ganglion neurons in the rat. J Biol Chem 279 29341-29350, 2004

99. Michael GJ and Priestley JV: Differential expression of the mRNA for the vanilloid receptor subtype 1 in cells of the adult rat dorsal root and nodose ganglia and its downregulation by axotomy. J Neurosci 19: 1844-1854, 1999.

100. Chung MK and Campbell JN: Use of capsaicin to treat pain: Mechanistic and therapeutic considerations. Pharmaceuticals (Basel) 9: 66, 2016

101.Davis JB, Gray J, Gunthorpe MJ, Hatcher JP, Davey PT, Overend P, Harries MH, Latcham J, Clapham C, Atkinson K, et al: Vanilloid receptor-1 is essential for inflammatory therma hyperalgesia. Nature 405: 183-187, 2000.

102. Julius D and Basbaum AI: Molecular mechanisms of nociception. Nature 413: 203-210, 2001

103. Mezey E, Tóth ZE, Cortright DN, Arzubi MK, Krause JE, Elde R, Guo A, Blumberg PM and Szallasi A: Distribution of mRNA for vanilloid receptor subtype 1 (VR1), and VR1-like immunoreactivity, in the central nervous system of the rat and human. Proc Natl Acad Sci USA 97: 3655-3660, 2000.

104. Fernandes ES, Fernandes MA and Keeble JE: The functions of TRPA1 and TRPV1: Moving away from sensory nerves. Br J Pharmacol 166: 510-521, 2012.

105. Roosterman D, Goerge T, Schneider SW, Bunnett NW and Steinhoff M: Neuronal control of skin function: The skin as a neuroimmunoendocrine organ. Physiol Rev 86: 1309-1379, 2006.

106. Southall MD, Li T, Gharibova LS, Pei Y, Nicol GD and Travers JB: Activation of epidermal vanilloid receptor-1 induces release of proinflammatory mediators in human keratinocytes. J Pharmacol Exp Ther 304: 217-222, 2003

107. Kim SJ, Lee SA, Yun SJ, Kim JK, Park JS, Jeong HS, Lee JH, Moon SJ and Won YH: Expression of vanilloid receptor 1 in cultured fibroblast. Exp Dermatol 15: 362-367, 2006.

108. Treede RD, Meyer RA, Raja SN and Campbell JN: Peripheral and central mechanisms of cutaneous hyperalgesia. Prog Neurobiol 38: 397-421, 1992.

109. Southall MD and Vasko MR: Prostaglandin receptor subtypes, EP3C and EP4, mediate the prostaglandin E2-induced cAMP production and sensitization of sensory neurons. J Biol Chem 276: 16083-16091, 2001.

110. Gábor M and Rázga Z: Development and inhibition of mouse ear oedema induced with capsaicin. Agents Actions 36: 83-86, 1992.

111. Lee YM, Kim YK and Chung JH: Increased expression of TRPV1 channel in intrinsically aged and photoaged human skin in vivo. Exp Dermatol 18: 431-436, 2009.

112. Lee YM, Kang SM and Chung JH: The role of TRPV1 channel in aged human skin. J Dermatol Sci 65: 81-85, 2012.
113. Lee YM, Kim YK, Kim KH, Park SJ, Kim SJ and Chung JH: A novel role for the TRPV1 channel in UV-induced matrix metalloproteinase (MMP)-1 expression in $\mathrm{HaCaT}$ cells. J Cell Physiol 219: 766-775, 2009.

114. Bíró T, Maurer M, Modarres S, Lewin NE, Brodie C, Acs G, Acs P, Paus R and Blumberg PM: Characterization of functional vanilloid receptors expressed by mast cells. Blood 91 1332-1340, 1998.

115. Căruntu C, Boda D, Musat S, Căruntu A and Mandache E Stress-induced mast cell activation in glabrous and hairy skin. Mediators Inflamm 2014: 105950, 2014.

116. Shim WS, Tak MH, Lee MH, Kim M, Kim M, Koo JY, Lee CH, Kim $\mathrm{M}$ and Oh U: TRPV1 mediates histamine-induced itching via the activation of phospholipase A2 and 12-lipoxygenase. J Neurosci 27: 2331-2337, 2007.

117. Bodó E, Bíró T, Telek A, Czifra G, Griger Z, Tóth BI, Mescalchin A, Ito T, Bettermann A, Kovács L, et al: A hot new twist to hair biology: Involvement of vanilloid receptor-1 (VR1/TRPV1) signaling in human hair growth control. Am J Pathol 166: 985-998, 2005.

118. Holzer P: Local effector functions of capsaicin-sensitive sensory nerve endings: Involvement of tachykinins, calcitonin gene-related peptide and other neuropeptides. Neuroscience 24 739-768, 1988

119. Richardson JD and Vasko MR: Cellular mechanisms of neurogenic inflammation. J Pharmacol Exp Ther 302: 839-845, 2002.

120. Birklein F and Schmelz M: Neuropeptides, neurogenic inflammation and complex regional pain syndrome (CRPS). Neurosci Lett 437: 199-202, 2008.

121. Maggi CA and Meli A: The sensory-efferent function of capsaicin-sensitive sensory neurons. Gen Pharmacol 19: 1-43, 1988.

122. Botchkarev VA, Eichmüller S, Peters EM, Pietsch P, Johansson O, Maurer M and Paus R: A simple immunofluorescence technique for simultaneous visualization of mast cells and nerve fibers reveals selectivity and hair cycle-dependent changes in mast cell - nerve fiber contacts in murine skin. Arch Dermatol Res 289: 292-302, 1997.

123. Ansel JC, Brown JR, Payan DG and Brown MA: Substance P selectively activates TNF-alpha gene expression in murine mast cells. J Immunol 150: 4478-4485, 1993.

124. Kowalski ML and Kaliner MA: Neurogenic inflammation, vascular permeability, and mast cells. J Immunol 140: 3905-3911, 1988.

125. Luo D, Zhang YW, Peng WJ, Peng J, Chen QQ, Li D, Deng HW and Li YJ: Transient receptor potential vanilloid 1-mediated expression and secretion of endothelial cell-derived calcitonin gene-related peptide. Regul Pept 150: 66-72, 2008.

126. Price RC, Gandhi W, Nadeau C, Tarnavskiy R, Qu A, Fahey E, Stone L and Schweinhardt P: Characterization of a novel capsaicin/heat ongoing pain model. Eur J Pain 22: 370-384, 2018.

127. Szolcsányi J: Capsaicin and sensory neurones: A historical perspective. In: Capsaicin as a Therapeutic Molecule. Springer, Basel, pp1-37, 2014.

128. Simone DA, Ngeow JY, Putterman GJ and LaMotte RH: Hyperalgesia to heat after intradermal injection of capsaicin. Brain Res 418: 201-203, 1987.

129. LaMotte RH, Shain CN, Simone DA and Tsai EF: Neurogenic hyperalgesia: Psychophysical studies of underlying mechanisms. J Neurophysiol 66: 190-211, 1991.

130. Torebjörk HE, Lundberg LE and LaMotte RH: Central changes in processing of mechanoreceptive input in capsaicin-induced secondary hyperalgesia in humans. J Physiol 448: 765-780, 1992.

131. Simone DA and Ochoa J: Early and late effects of prolonged topical capsaicin on cutaneous sensibility and neurogenic vasodilatation in humans. Pain 47: 285-294, 1991.

132. Carpenter SE and Lynn B: Vascular and sensory responses of human skin to mild injury after topical treatment with capsaicin. Br J Pharmacol 73: 755-758, 1981.

133. Schmelz M, Schmid R, Handwerker HO and Torebjörk HE: Encoding of burning pain from capsaicin-treated human skin in two categories of unmyelinated nerve fibres. Brain 123: 560-571, 2000

134. Simone DA, Baumann TK and LaMotte RH: Dose-dependent pain and mechanical hyperalgesia in humans after intradermal injection of capsaicin. Pain 38: 99-107, 1989.

135. Serra J, Campero M and Ochoa J: Flare and hyperalgesia after intradermal capsaicin injection in human skin. J Neurophysiol 80: 2801-2810, 1998. 
136.Kinnman E, Nygårds EB and Hansson P: Peripheral $\alpha$-adrenoreceptors are involved in the development of capsaicin induced ongoing and stimulus evoked pain in humans. Pain 69: $79-85,1997$.

137. Ma XL, Zhang FX, Dong F, Bao L and Zhang X: Experimental evidence for alleviating nociceptive hypersensitivity by single application of capsaicin. Mol Pain 11: 22, 2015.

138. White JPM, Urban L and Nagy I: TRPV1 function in health and disease. Curr Pharm Biotechnol 12: 130-144, 2011.

139. Amaya F, Shimosato G, Nagano M, Ueda M, Hashimoto S, Tanaka Y, Suzuki H and Tanaka M: NGF and GDNF differentially regulate TRPV1 expression that contributes to development of inflammatory thermal hyperalgesia. Eur J Neurosci 20: 2303-2310, 2004.

140. Urban L, White JPM and Nagy I: Molecular structure of transient receptor potential vanilloid type 1 ion channel (TRPV1). Curr Pharm Biotechnol 12: 115-121, 2011.

141. Tympanidis P, Casula MA, Yiangou Y, Terenghi G, Dowd P and Anand P: Increased vanilloid receptor VR1 innervation in vulvodynia. Eur J Pain 8: 129-133, 2004

142. Yilmaz Z, Renton T, Yiangou Y, Zakrzewska J, Chessell IP, Bountra $C$ and Anand P: Burning mouth syndrome as a trigeminal small fibre neuropathy: Increased heat and capsaicin receptor TRPV1 in nerve fibres correlates with pain score. J Clin Neurosci 14: 864-871, 2007.

143. Haanpää $M$ and Treede RD: Capsaicin for neuropathic pain: Linking traditional medicine and molecular biology. Eur Neurol 68: 264-275, 2012.

144.Ji RR, Samad TA, Jin SX, Schmoll R and Woolf CJ: p38 MAPK activation by NGF in primary sensory neurons after inflammation increases TRPV1 levels and maintains heat hyperalgesia. Neuron 36: 57-68, 2002.

145. Jordt SE, Tominaga M and Julius D: Acid potentiation of the capsaicin receptor determined by a key extracellular site. Proc Natl Acad Sci USA 97: 8134-8139, 2000.

146. Huang J, Zhang X and McNaughton PA: Inflammatory pain: The cellular basis of heat hyperalgesia. Curr Neuropharmacol 4: 197-206, 2006.

147. Szallasi A and Blumberg PM: Specific binding of resiniferatoxin, an ultrapotent capsaicin analog, by dorsal root ganglion membranes. Brain Res 524: 106-111, 1990.

148. Bleakman D, Brorson JR and Miller RJ: The effect of capsaicin on voltage-gated calcium currents and calcium signals in cultured dorsal root ganglion cells. Br J Pharmacol 101: 423-431, 1990.

149.Docherty RJ, Robertson B and Bevan S: Capsaicin causes prolonged inhibition of voltage-activated calcium currents in adult rat dorsal root ganglion neurons in culture. Neuroscience 40: 513-521, 1991.
150. Dray A, Bettaney $\mathrm{J}$ and Forster P: Actions of capsaicin on peripheral nociceptors of the neonatal rat spinal cord-tail in vitro: Dependence of extracellular ions and independence of second messengers. Br J Pharmacol 101: 727-733, 1990.

151. Anand P, Bloom SR and McGregor GP: Topical capsaicin pretreatment inhibits axon reflex vasodilatation caused by somatostatin and vasoactive intestinal polypeptide in human skin. $\mathrm{Br}$ J Pharmacol 78: 665-669, 1983.

152.Bjerring $\mathrm{P}$ and Arendt-Nielsen L: Inhibition of histamine skin flare reaction following repeated topical applications of capsaicin. Allergy 45: 121-125, 1990

153. Tóth-Kása I,Jancsó G, Bognár A, Husz S and Obál F Jr: Capsaicin prevents histamine-induced itching. Int J Clin Pharmacol Res 6 : $163-169,1986$

154. Winter J, Bevan S and Campbell EA: Capsaicin and pain mechanisms. Br J Anaesth 75: 157-168, 1995.

155. Hartel M, di Mola FF, Selvaggi F, Mascetta G, Wente MN, Felix K, Giese NA, Hinz U, Di Sebastiano P, Büchler MW, et al: Vanilloids in pancreatic cancer: Potential for chemotherapy and pain management. Gut 55: 519-528, 2006.

156. Shin CY, Shin J, Kim BM, Wang MH, Jang JH, Surh YJ and Oh U: Essential role of mitochondrial permeability transition in vanilloid receptor 1-dependent cell death of sensory neurons. Mol Cell Neurosci 24: 57-68, 2003.

157. Athanasiou A, Smith PA, Vakilpour S, Kumaran NM, Turner AE, Bagiokou D, Layfield R, Ray DE, Westwell AD, Alexander SP, et al: Vanilloid receptor agonists and antagonists are mitochondrial inhibitors: How vanilloids cause non-vanilloid receptor mediated cell death. Biochem Biophys Res Commun 354: 50-55, 2007.

158. Buck SH and Burks TF: The neuropharmacology of capsaicin: Review of some recent observations. Pharmacol Rev 38: $179-226,1986$

159. Chung K, Klein CM and Coggeshall RE: The receptive part of the primary afferent axon is most vulnerable to systemic capsaicin in adult rats. Brain Res 511: 222-226, 1990.

160. Wood JN, Coote PR, Minhas A, Mullaney I, McNeill M and Burgess GM: Capsaicin-induced ion fluxes increase cyclic GMP but not cyclic AMP levels in rat sensory neurones in culture. J Neurochem 53: 1203-1211, 1989.

(i) $(9)$ This work is licensed under a Creative Commons Attribution-NonCommercial-NoDerivatives 4.0 International (CC BY-NC-ND 4.0) License. 